Supporting Information

\title{
Biobased, Nonisocyanate, 2K Polyurethane Coatings Produced from Polycarbamate and Dialdehyde Crosslinking
}

\author{
Samantha D. Silbert, ${ }^{1}$ Eric M. Serum,${ }^{2}$ John LaScala, ${ }^{3}$ Mukund P. Sibi,${ }^{2 *}$ Dean C.
}

Webster $^{1^{*}}$

${ }^{1}$ Department of Coatings and Polymeric Materials; North Dakota State University, P. O. Box 6050, Department 2760, Fargo, ND 58108 USA

${ }^{2}$ Department of Chemistry and Biochemistry, North Dakota State University, P.O. Box 6050, Department 2735, Fargo, ND 58108 USA

${ }^{3}$ RDRL-WM, U.S. Army Research Laboratory, 4600 Deer Creek Loop, Aberdeen Proving

Ground, Adelphi, MD 21005 USA

Pages: 10

Figures: 9

Tables: 1

${ }^{*}$ Corresponding authors. Email: dean.webster@ndsu.edu, Phone: +1-701-231-8709 mukund.sibi@ndsu.edu, Phone: +1-701-231-8051 


\section{Synthesis of Methoxy Sucrose Soyate Polyol (MSSP)}

The ring-opening reaction of ESS with methanol to produce MSSP was completed using a method reported in Nelson et al. ${ }^{1}$ In a one liter, 3-neck round bottom flask equipped with thermocouple, overhead mechanical stirrer, and addition funnel, $215 \mathrm{~g}$ methanol, $3.75 \mathrm{~g}$ of $48 \% \mathrm{wt}$ TFBA solution, and $13.4 \mathrm{~g}$ DI water were added. The mixture was heated to $50{ }^{\circ} \mathrm{C}$ and dropwise addition of $200 \mathrm{~g}$ of epoxidized sucrose soyate dissolved in $100 \mathrm{~g}$ of chloroform commenced at a rate of $2 \mathrm{~mL} / \mathrm{min}$. After completing the addition, the temperature was held for 20 more minutes and then cooled to room temperature. Sodium bicarbonate solution was added and the mixture stirred for 20 more minutes. Stirring was then halted and the mixture phase separated overnight. The following day, the top layer in the flask was removed and the resin was diluted with dichloromethane and transferred to a $1 \mathrm{~L}$ separatory funnel. The mixture was washed 8 times with DI water or until a $\mathrm{pH}$ strip placed into the removed water postseparation read a neutral $\mathrm{pH}$. Solvent was removed via rotary evaporation and the transparent resin stored. The resin's OH equivalent weight (OHEW) was assessed using ${ }^{31} \mathrm{P}$ NMR (see below).

\section{Characterization of cis, trans 1,4-Cyclohexane Dicarboxaldehyde (CHDA)}

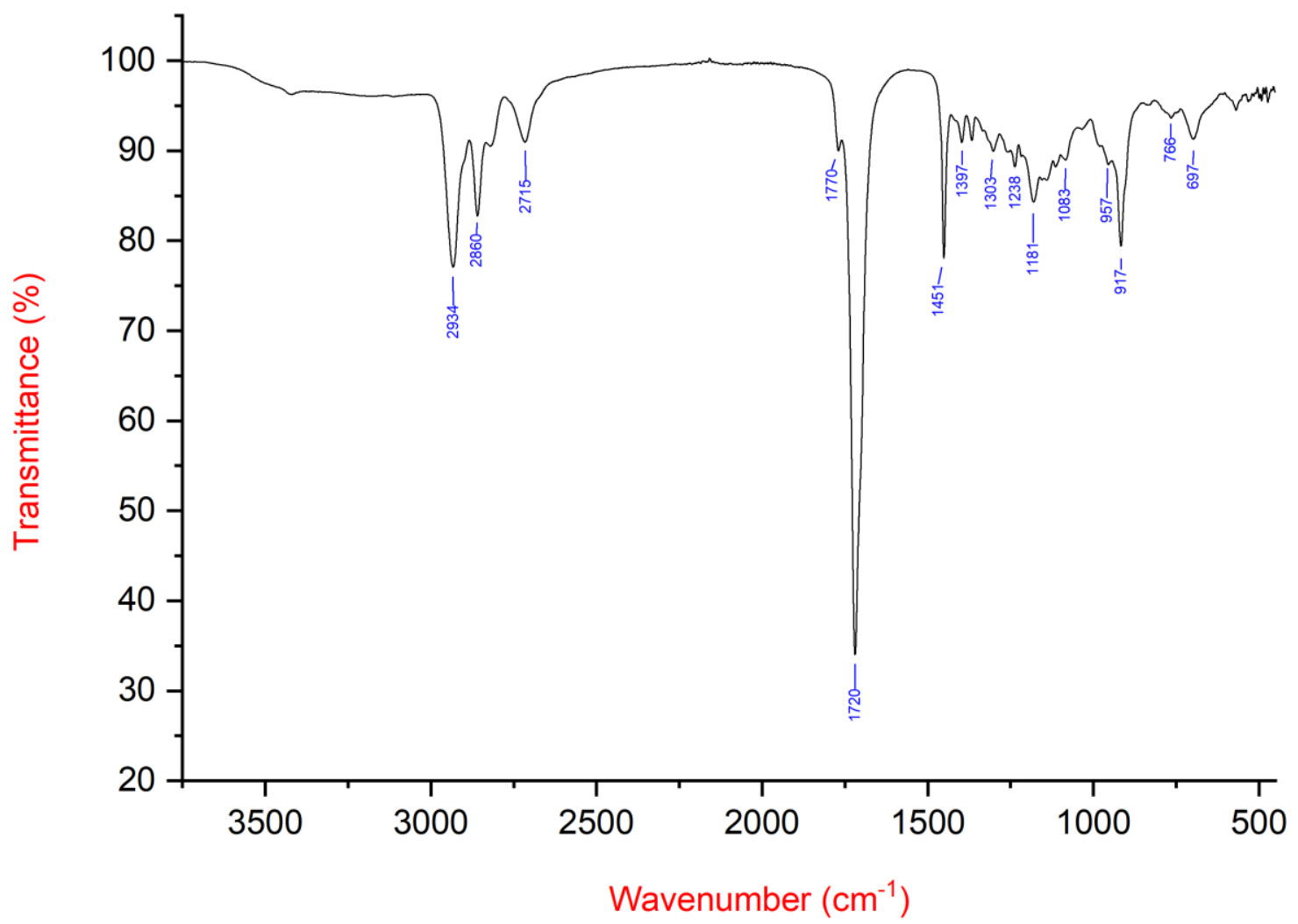

Figure S1. FTIR spectrum of Column Purified CHDA 


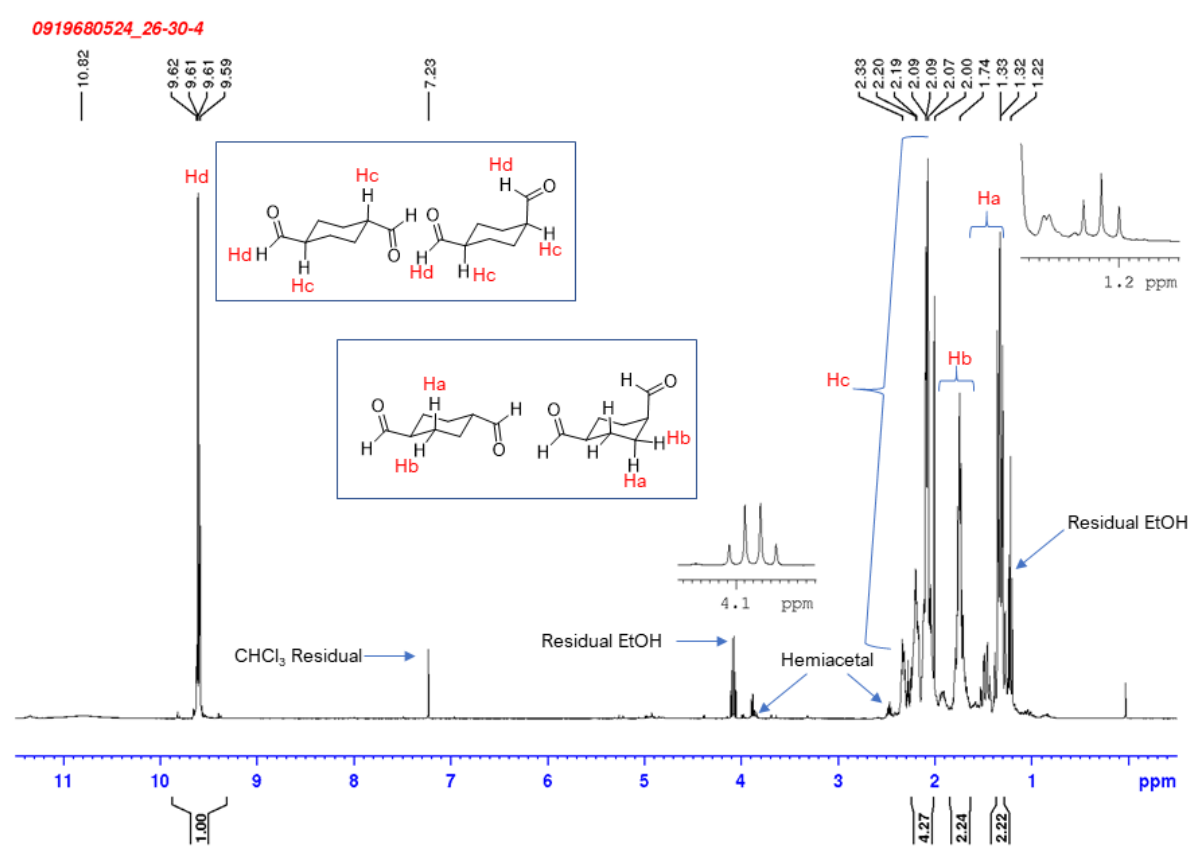

Figure S2. ${ }^{1} \mathrm{H}$ NMR spectrum of Column Purified CHDA with assignments used in curing.

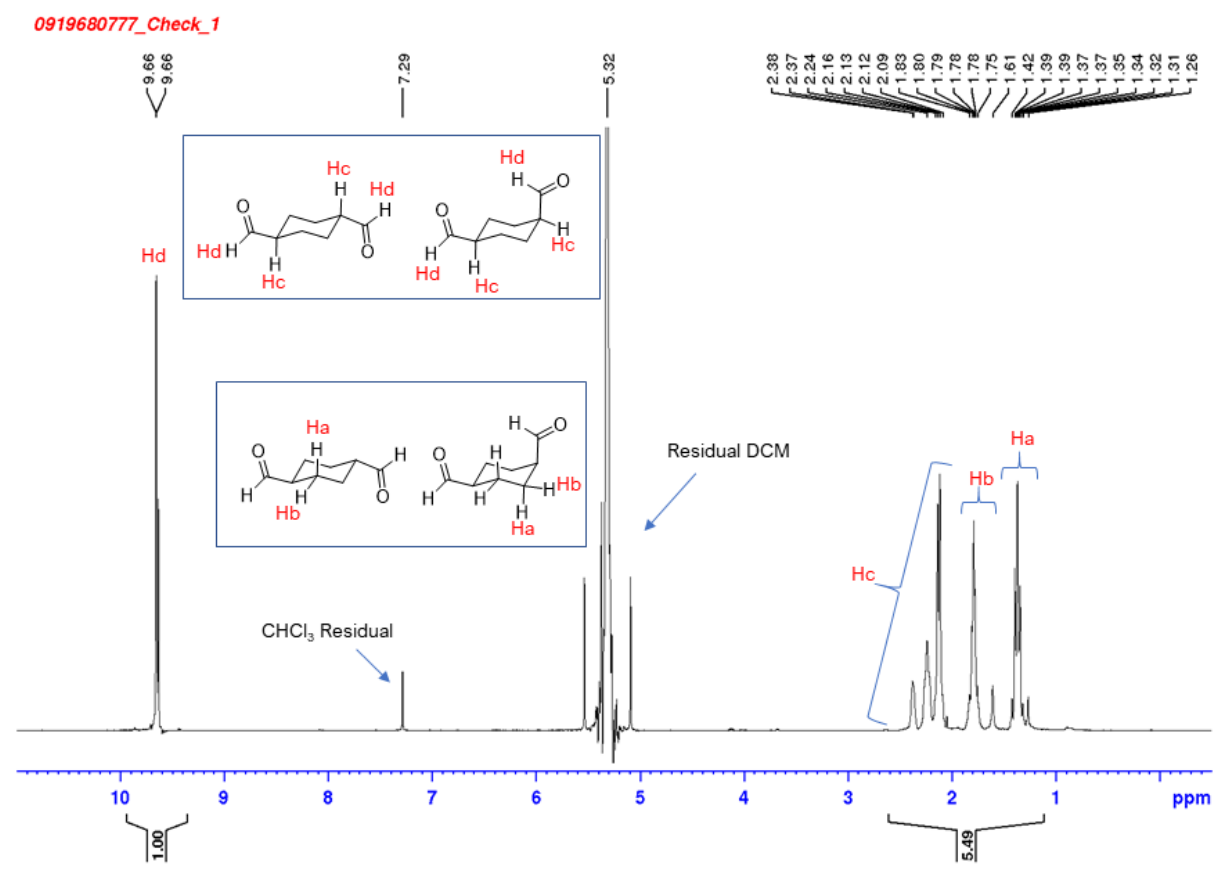

Figure S2A. ${ }^{1}$ H NMR spectrum of Pure CHDA with methylene chloride 


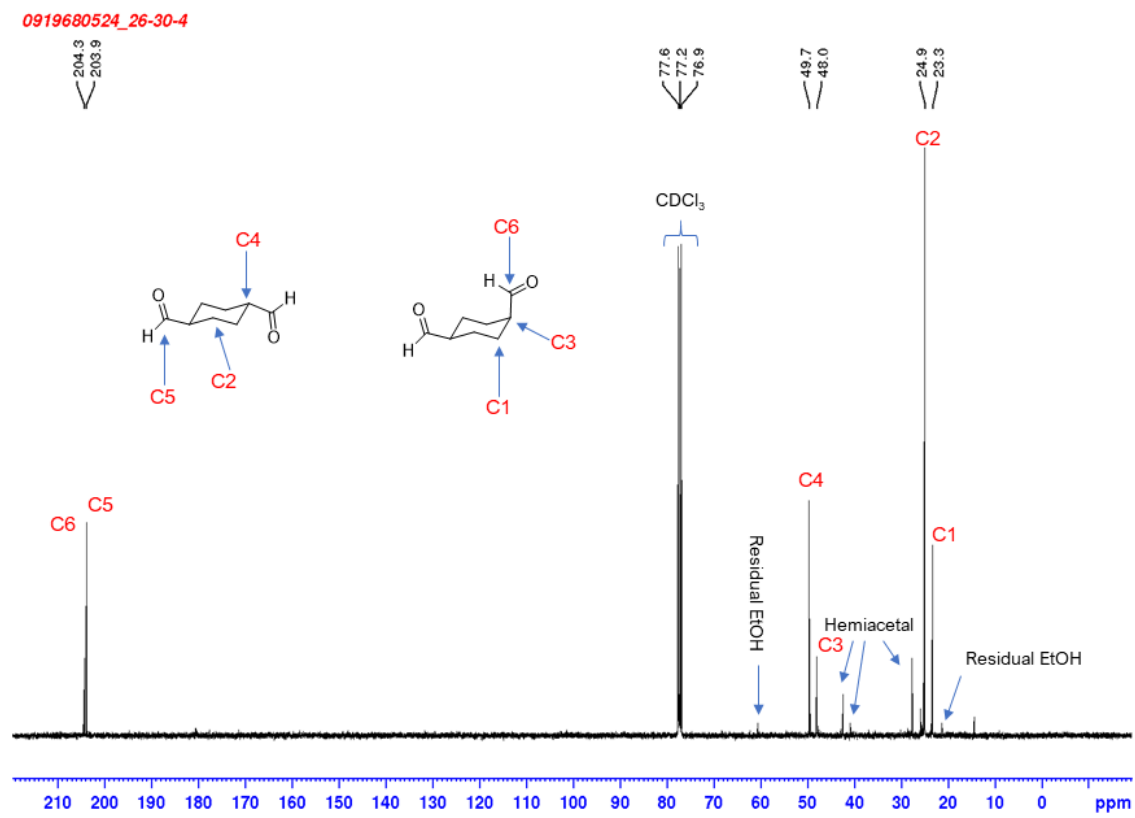

Figure S3. ${ }^{13} \mathrm{C}$ NMR spectrum of Column Purified CHDA with assignments used in curing.

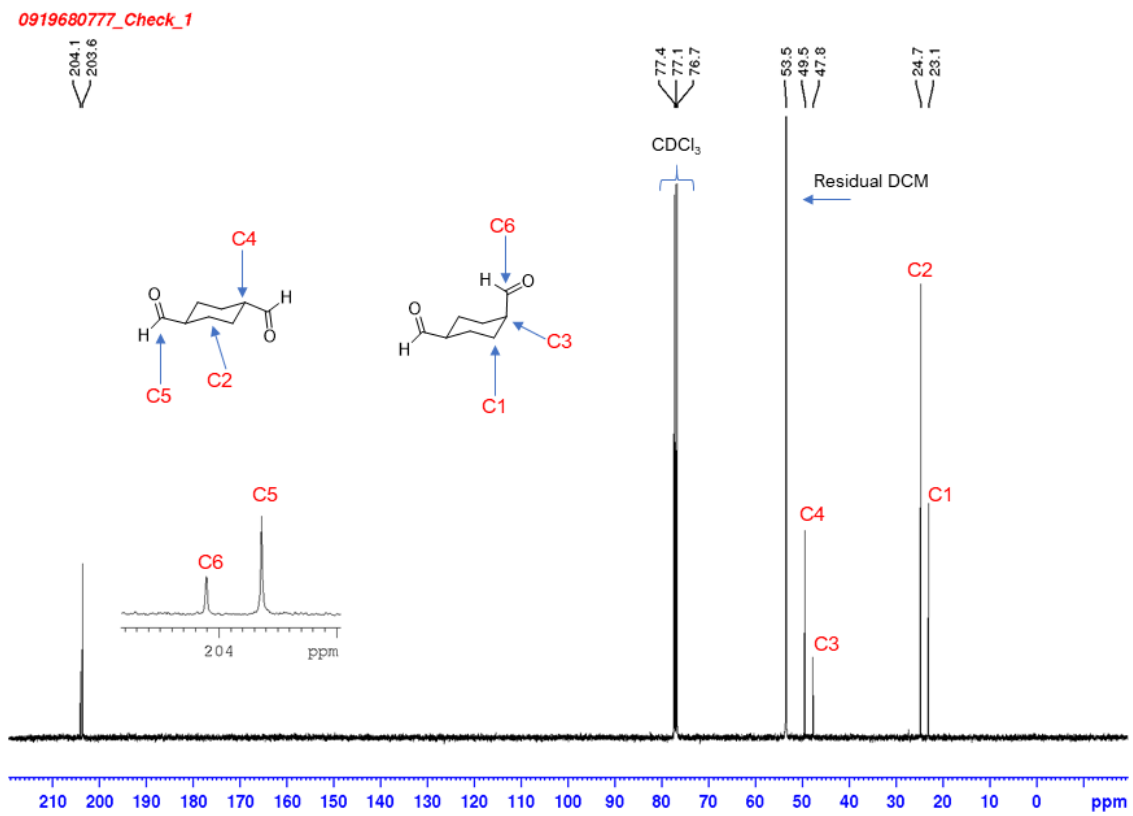

Figure S3A. ${ }^{13} \mathrm{C}$ NMR spectrum of pure CHDA with methylene chloride 


\section{Reaction optimization of DFF synthesis}

Table S1 Chemoselective oxidation of HMF using manganese dioxide

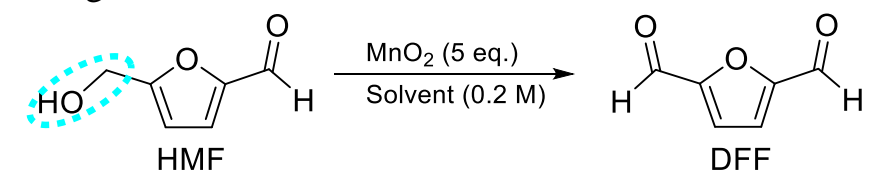

\begin{tabular}{llll} 
Entry & Solvent & Time (h) & Yield $(\%)^{\mathrm{a}}$ \\
\hline 1 & \multirow{2}{*}{$\mathrm{CH}_{2} \mathrm{Cl}_{2}$} & 3 & 76 \\
2 & & $6^{\mathrm{b}}$ & 75 \\
\hline 3 & & 1.5 & 73 \\
4 & EtOAc & $1.5^{\mathrm{c}}$ & 68 \\
5 & & $2.5^{\mathrm{b}}$ & 82 \\
\hline 6 & $\mathrm{CPME}^{\mathrm{d}}$ & 0.5 & 72 \\
\hline
\end{tabular}

a: isolated (\%); b: no moisture trap; c: water replaced methanol in the workup followed by liquid-liquid extraction; $\mathrm{d}$ : CPME = Cyclopentyl methylether

Methods have been reported in the literature for the sustainable and selective conversion of the primary alcohol of HMF to an aldehyde. ${ }^{2}$ Manganese dioxide ${ }^{3}\left(\mathrm{MnO}_{2}\right)$ is a well-known and mild-oxidant with great potential for use in chemoselective transformations. Our goal was to develop a selective oxidation protocol using $\mathrm{MnO}_{2}$ and a recommended ${ }^{4}$ solvent without compromising yield. Previous replacement of DCM with toluene along with attenuation of excess oxidizer to less than 3 equivalents of $\mathrm{MnO}_{2}$ was reported without sacrificing yield during this heterogeneous oxidation. ${ }^{5-6}$ Freshly prepared $\mathrm{MnO}_{2}$ is much more reliable in this process although commercial $\mathrm{MnO}_{2}$ has worked well when azeotropic distillation was used to dry the reaction mixture. ${ }^{7-8}$ Unfortunately, such strongly dehydrating conditions favor oligo-acetal formation.

The halogenated solvent, dichloromethane, performed well for the conversion of HMF to DFF (entries 1 and 2, Table S1) following $3 \mathrm{~h}$ and $6 \mathrm{~h}$ of distillation respectively. Ethyl acetate was targeted as a dichloromethane replacement (entries 3-5, Table S1) to good effect (yields between 68 and 82\%). Surprisingly, refluxing in ethyl acetate without a moisture trap resulted in significantly higher yields (entry 4, Table S1). A 'green solvent' used in process chemistry, ${ }^{9}$ cyclopentyl methyl ether (CPME), also gave similar yield (entry 6, Table S1) to that observed with ethyl acetate following only 30 minutes of distillation. These experiments demonstrate that we can prepare 2,5-diformylfuran in high yield using 'green solvents'. 


\section{Characterization of 2,5-diformylfuran (DFF)}

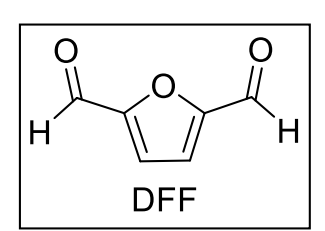

\section{2,5-Diformylfuran}

${ }^{1} \mathrm{H}$ (DMSO-d $\left.6400 \mathrm{MHz}\right): \delta 9.81(\mathrm{~s}, 1 \mathrm{H}), 7.67(\mathrm{~s}, 1 \mathrm{H}) ;{ }^{13} \mathrm{C}\left(\mathrm{DMSO}-\mathrm{d}_{6} 100 \mathrm{MHz}\right): \delta$ 180.7, 153.6, 122.0; ${ }^{1} \mathrm{H}\left(\mathrm{CDCl}_{3} 400 \mathrm{MHz}\right): \delta 9.84(\mathrm{~s}, 1 \mathrm{H}), 7.31(\mathrm{~s}, 1 \mathrm{H}) ;{ }^{13} \mathrm{C}\left(\mathrm{CDCl}_{3}\right.$ $100 \mathrm{MHz}$ ): $\delta$ 179.4, 154.4, 119.4; FTIR (ATR, Diamond, Neat): $\mathrm{cm}^{-1} 3132,3102$, 1673, 1561, 1512, 1412, 1269, 1239, 1188, 1042, 976, 958, 845, 797, 532.

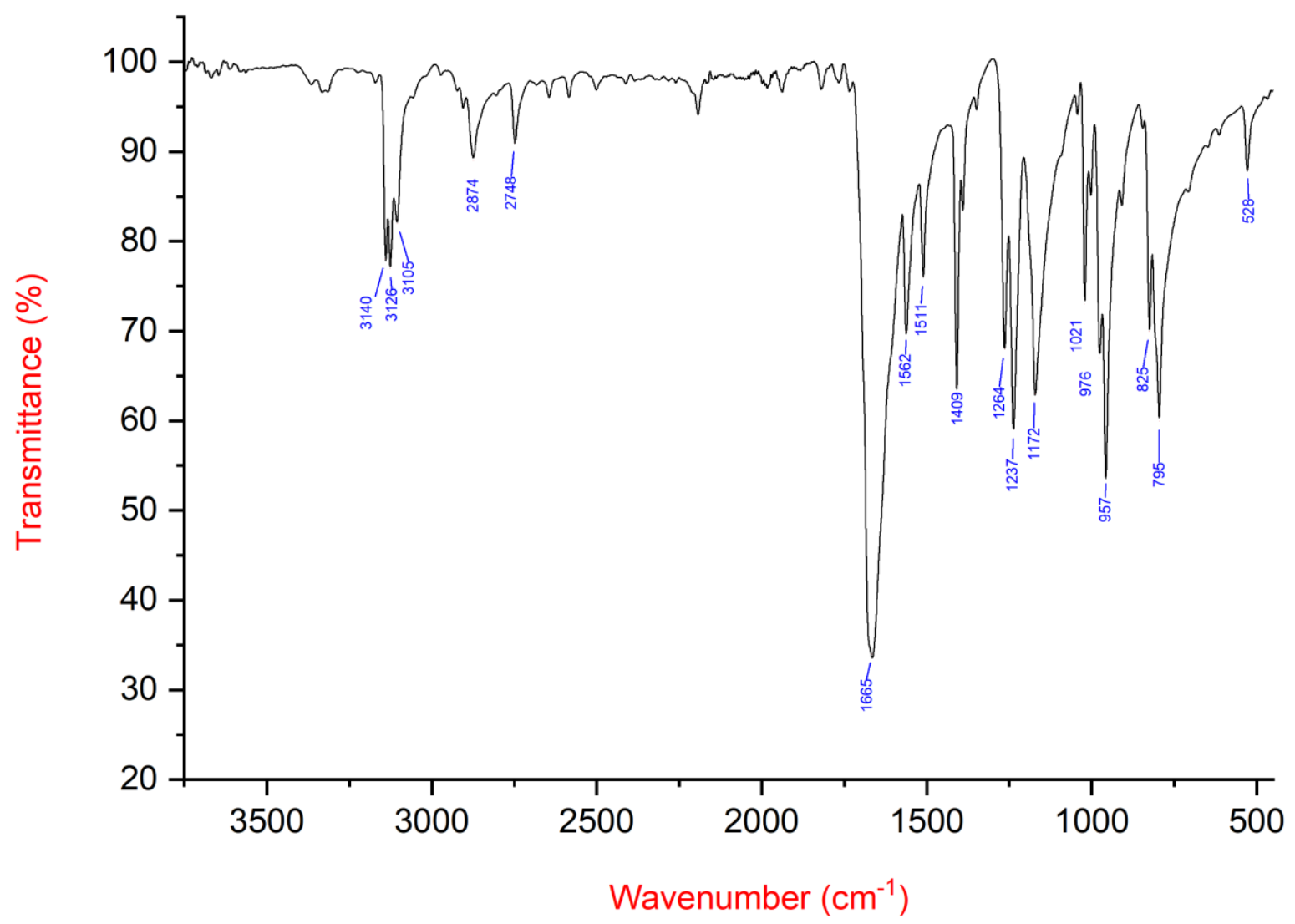

Figure S4. FTIR spectrum of 2,5-furandicarboxaldehyde. 


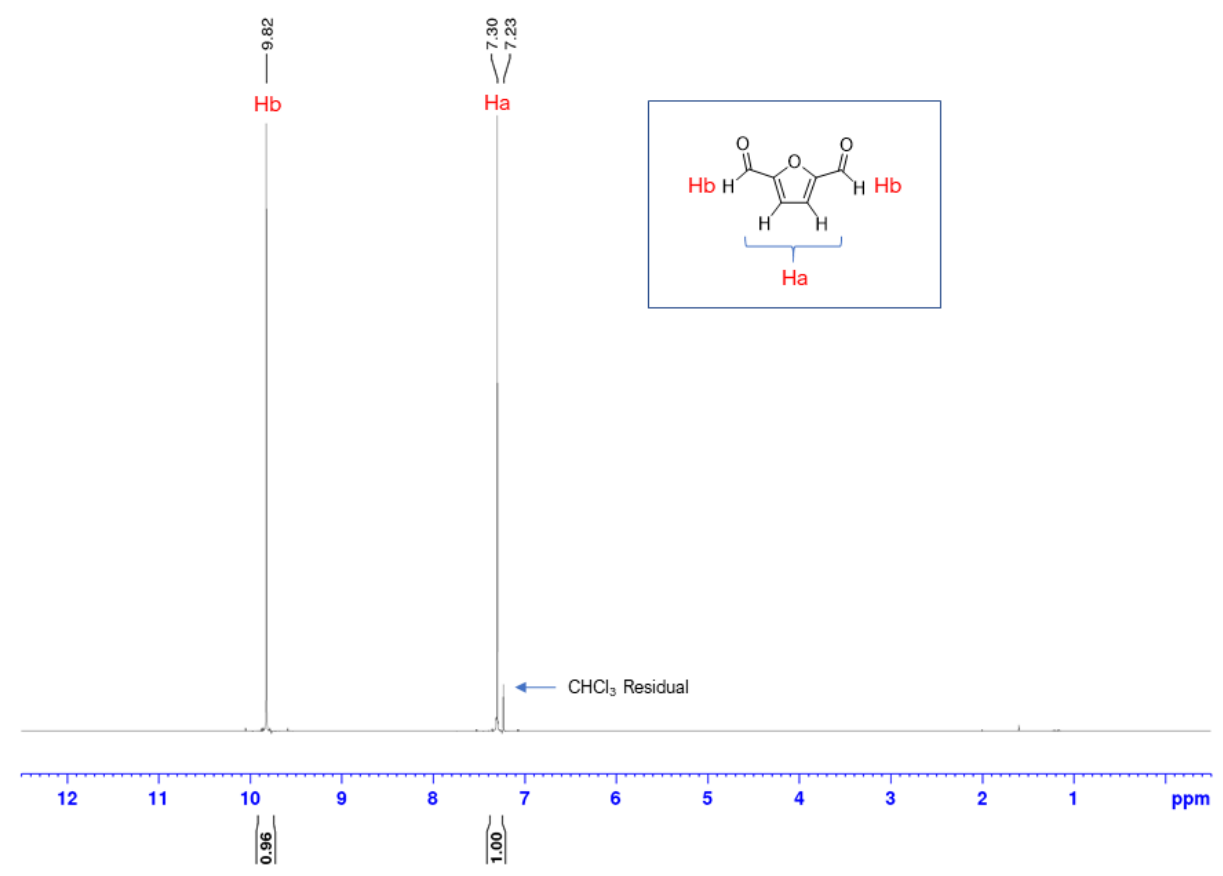

Figure S5. ${ }^{1} \mathrm{H}$ NMR spectrum of 2,5-furandicarboxyldehyde.

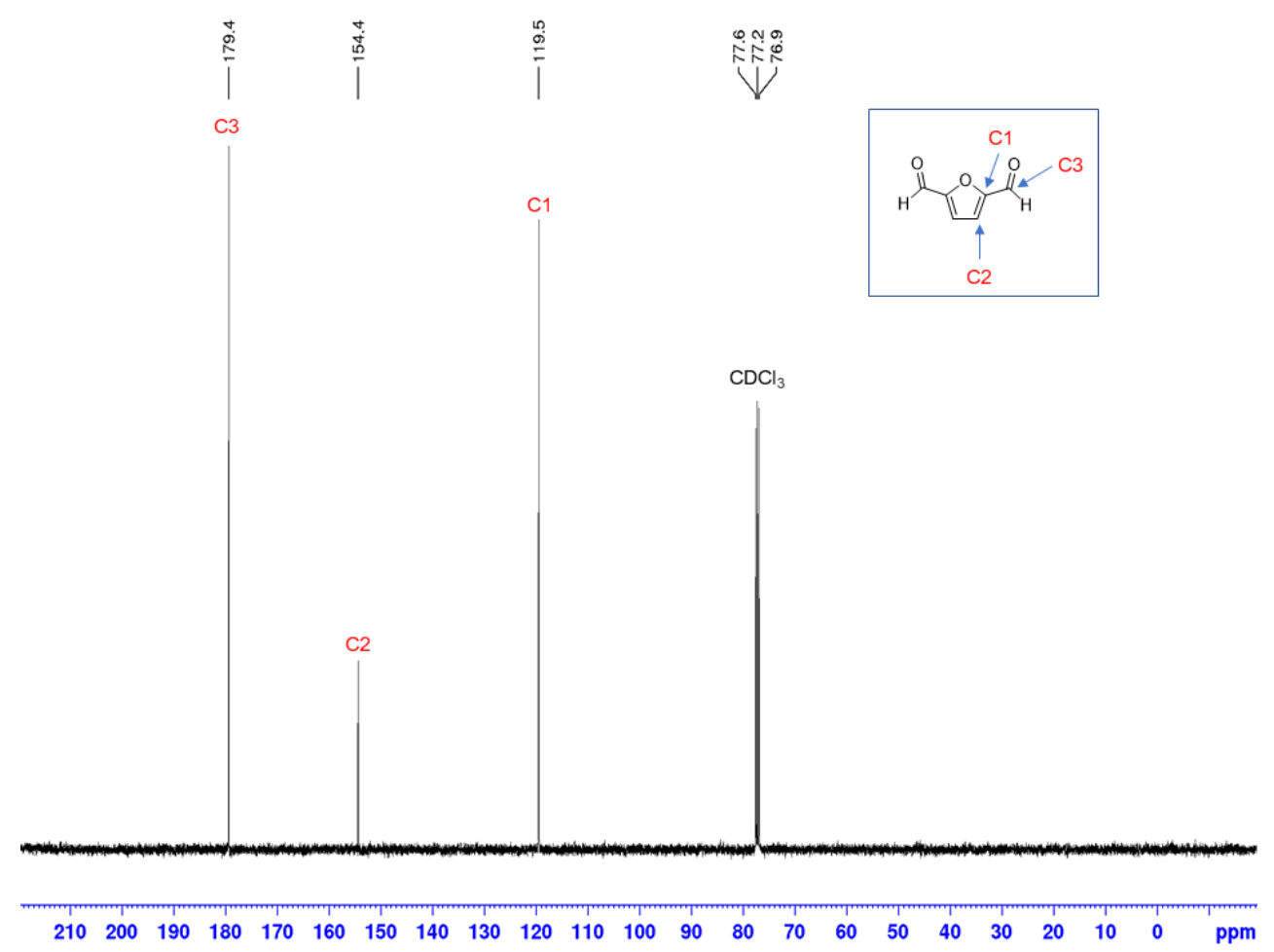

Figure S6. ${ }^{13} \mathrm{C}$ NMR spectrum of 2,5-furandicarboxaldehyde. 


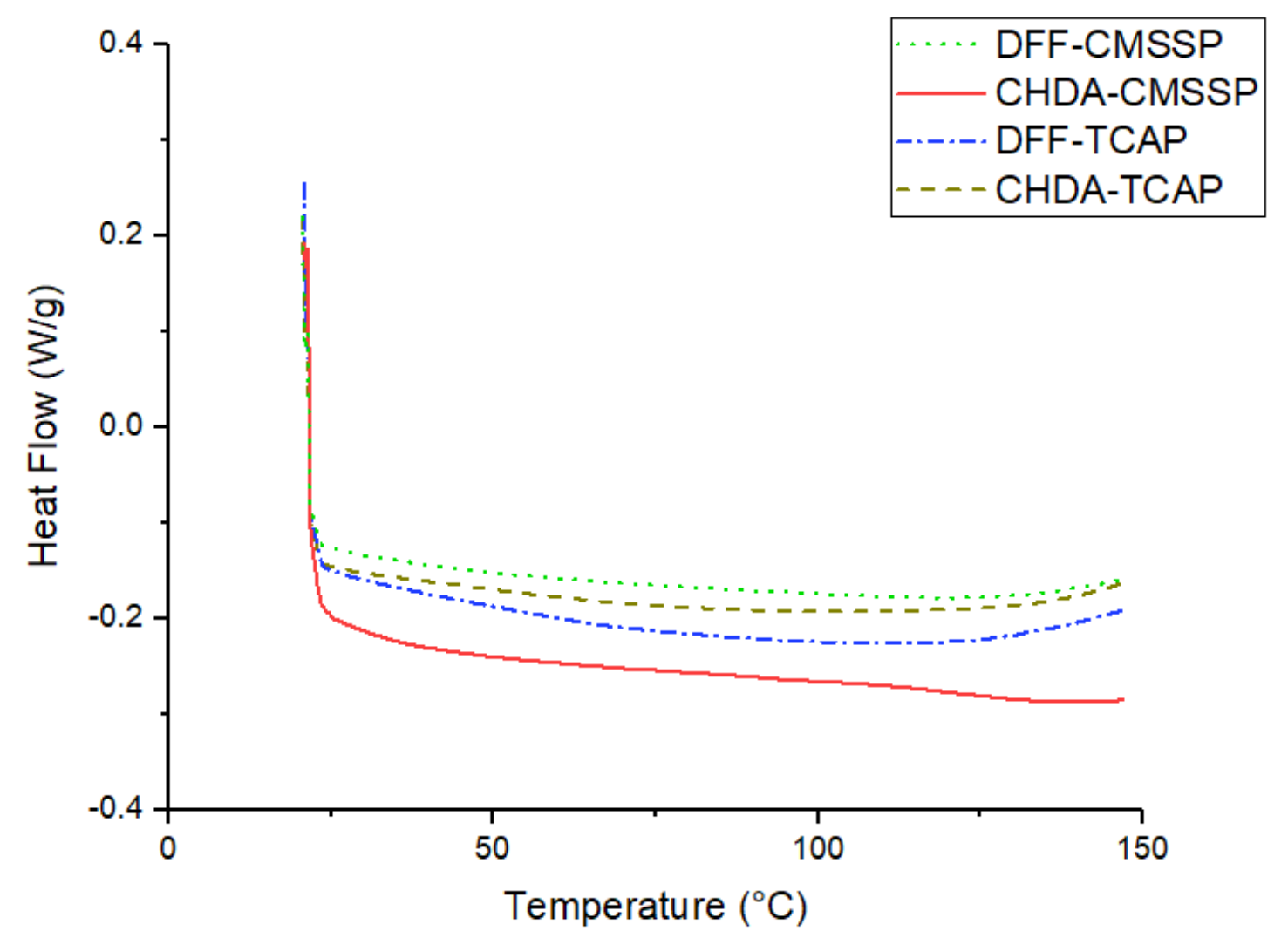

Figure S7. DSC second heating scan of cured coatings.

\section{${ }^{31}$ P NMR Procedure to Determine Hydroxyl Content of Resins}

The procedure was developed from a method stated in Adamopoulos. ${ }^{10}$ In a glass vial, $15-20 \mathrm{mg}$ of resin was weighed out. To this vial, $500 \mu \mathrm{L}$ of a $50 / 50$ by weight Pyridine/ $\mathrm{CDCl}_{3}$ mixture was added. The internal standard, 2-nitrophenol, was dissolved in a separate vial at $10-16 \mathrm{mg}$ in $1 \mathrm{~mL} \mathrm{Pyr} / \mathrm{CDCl}_{3}$ mixture to make the internal standard solution. Of this solution, $100 \mu \mathrm{L}$ was then added to the sample vial. In another separate vial, $11.4 \mathrm{mg}$ of chromium (III) acetylacetonate was added and dissolved in $1 \mathrm{~mL}$ weight Pyridine/ $\mathrm{CDCl}_{3}$ mixture and $50 \mu \mathrm{L}$ of this solution added to the sample vial. 2-Chloro-1,3,2dioxaphospholane (CDP) was added to the sample vial at 3:1 by volume reagent: estimated hydroxyl content of resin to ensure complete reaction of $\mathrm{OH}$ groups. Contents of the vial was transferred by micropipet into a Wilmad ${ }^{\mathrm{TM}}$ NMR sample tube of outer and inner diameters of $5 \mathrm{~mm}$ and $4 \mathrm{~mm}$ respectively and 7', length. ${ }^{31} \mathrm{P}$ NMR analysis was completed on an JEOL ECA Series $400 \mathrm{MHz}$ NMR Spectrometer with lock on No Solvent before running analysis. Samples were completed in duplicate and values averaged. 


\section{Hydroxyl Equivalent Weight}

Equation 1. OH Content of Sample and Internal Standard via ${ }^{31}$ PNMR

$v_{O H \text { Content }}=\frac{\int \mathrm{OH}_{\text {Resin }}}{\int O H_{\text {Internal Standard }}} \times$ mmol Internal Standard

Equation 2. OH Number of Resin

$O H \#_{\text {Resin }}=\frac{v_{O H \text { Content }}}{g \text { Sample }} \times 56.1\left(\frac{g}{\text { mol }}\right)=\frac{m g K O H}{\text { g Sample }}$

Equation 3. OH Equivalent Weight of Resin

$O H E W_{\text {Resin }}=\frac{56100 \frac{\mathrm{mg}}{\mathrm{mol}}}{O H \#}$

Equation 4. Carbamate Conversion of Polycarbamate Resin ${ }^{3}$

Carbamate Conversion $=\frac{O H \#_{\text {Polyol }}-O H \#_{\text {Polycarbamate }}}{O H \#_{\text {Polyol }}}$

Equation 5. Carbamate Equivalent Weight of Carbamate Resin ${ }^{3}$

Carbamate Equivalent Weight $=\frac{O H E W_{\text {Polyol }}+(43 \times \text { Carbamate Conversion })}{\text { Carbamate Conversion }}$ 


\section{References}

1. Nelson, T. J.; Masaki, B.; Morseth, Z.; Webster, D. C., Highly functional biobased polyols and their use in melamine-formaldehyde coatings. J. Coat. Technol. Res. 2013, 10 (6), 757-767.

2. Nocito, F.; Ventura, M.; Aresta, M.; Dibenedetto, A., Selective Oxidation of 5(Hydroxymethyl)furfural to DFF Using Water as Solvent and Oxygen as Oxidant with Earth-CrustAbundant Mixed Oxides. ACS Omega 2018, 3 (12), 18724-18729.

3. Evans, R. M., Oxidations by Manganese Dioxide in Neutral Media. Qart. Rev. Chem. Soc. 1959, 13 (1), 61-70.

4. Prat, D.; Wells, A.; Hayler, J.; Sneddon, H.; McElroy, C. R.; Abou-Shehada, S.; Dunn, P. J., CHEM21 Selection Guide of Classical- and Less Classical-Solvents. Green Chem. 2016, 18 (1), 288-296.

5. Serum, E. M.; Selvakumar, S.; Zimmermann, N.; Sibi, M. P., Valorization of 2,5-Furandicarboxylic Acid. Diels-Alder Reactions with Benzyne. Green Chem. 2018, 20 (7), 1448-1454.

6. Vijjamarri, S.; Streed, S.; Serum, E. M.; Sibi, M. P.; Du, G., Polymers from Bioderived Resources: Synthesis of Poly(silylether)s from Furan Derivatives Catalyzed by a Salen-Mn(V) Complex. ACS Sust. Chem. \& Eng. 2018, 6 (2), 2491-2497.

7. Tsuboi, S.; Ishii, N.; Sakai, T.; Tari, I.; Utaka, M., Oxidation of Alcohols with Electrolytic Manganese Dioxide. Its Application for the Synthesis of Insect Pheromones. Bull. Chem. Soc. Jpn. 1990, 63 (7), 1888-1893.

8. Goldman, I., Activation of Manganese Dioxide by Azeotropic Removal of Water. J. Org. Chem. 1969, 34 (6), 1979-1981.

9. Watanabe, K.; Yamagiwa, N.; Torisawa, Y., Cyclopentyl Methyl Ether as a New and Alternative Process Solvent. Org. Process Res. Dev. 2007, 11 (2), 251-258.

10. Adamopoulos, L., Understanding the formation of sugar fatty acid esters. 2006, NC State University Libraries. Master's Thesis in Wood and Paper Science. 